\title{
On improving the Russian laws in the field of city planning
}

\author{
Emma Shariapova $^{1 *}$, Natalia Pisareva ${ }^{1}$ and Anna Kozlova ${ }^{1}$ \\ ${ }^{1}$ Saint Petersburg State University of Architecture and Civil Engineering, 190005, 4, Vtoraja \\ Krasnoarmejskaja ul., St. Petersburg, Russia
}

\begin{abstract}
: the article examines the issues of administrative punishments for city planning offences in the Russian Federation. Construction offences oftentimes cause severe consequences. However, it is possible to prevent them through the improvement of administrative law. The authors research the legal components of administrative offences in construction. Several gaps have been identified that are related to non-system unspecific representation of offences which combines multiple behavior patterns formed at various construction stages of capital construction facilities. As a result of the study, several suggestions have been drafted, the implementation of which would promote both preventive measures and restraint of violations of law, primarily, on behalf of government officials.
\end{abstract}

\section{Introduction}

City planning is an essential part of state and community existence and development. City Planning Code of the Russian Federation (hereinafter referred to as CPC) provides the definition of sustainable land use [1]. The sustainable land use is the essence of sustainable development that gets particular attention of the President of the Russian Federation who determines the country's growth areas.

Sustainable development was the main subject of the International Economic Forum that took place in 2019 and formulated that sustainability requires certain mechanisms, which, on the one hand, will promote the further quality of life improvement for the Russian citizens, and, on the other hand, will continue the measures to protect and restore natural resources.

According to p. 1 Art. 1 of CPC of the Russian Federation, city planning activities include any activities to develop land, including cities and towns, carried out as part of land use planning, urban development zoning, area planning, civil and architectural engineering, construction, capital repairs, reconstruction, demolition of construction projects, buildings and structures maintenance, and improvement of areas [1]. Construction as a process is erection of buildings, structures, and facilities [1]. Thus, city planning is a wider ranging concept than construction alone.

\footnotetext{
*Corresponding author: sharyapova.emma@yandex.ru
} 
Construction is a process which includes several stages: acquisition of land property, engineering surveying, expert assessment of engineering surveying, civil and architectural engineering, expert assessment of architectural project for capital construction facilities, obtaining a construction permit, the process of construction of capital construction facilities, compliance assessment as a result of construction monitoring and supervision, and commissioning.

All these construction stages are closely interrelated and should be completed in a certain order. It is impossible to implement several stages simultaneously. The quality of each stage should be controlled; otherwise, any potential flaws and errors would lead to further adverse consequences like complicated adjustment, deadline extension, or work cost increase. Construction facilities are considered high-risk sites. Violation of specified standards might cause damage to life or health of people or violation of environmental standards that are protected and guaranteed by the Constitution of the Russian Federation [2].

City planning legal arrangement consists of many parties. Those include customers, technical customers, investors, architects, designers, developers, technical directors, contractors, executive authorities (when conducting an assessment of design documentation and the results of engineering surveying, when issuing an approval for construction and commissioning), etc. The mentioned parties may be individuals, corporate entities, or government officials.

A customer is a person who enters into a construction project agreement.

An investor is a person who invests his/her funds into a construction project with the goal of gaining profit [3]. The profit might come as percentage deductions from sale and purchase or lease agreements.

An architect comes up with an architectural concept, i. e. he/she decides on the exterior and interior of the future building, its spatial, planning and functional organization. Based on the architectural solution, a designer, along with an architect, accepts the concept, which contains engineering, technical, functional, firefighting, sanitary, epidemiological, and environmental requirements for the constructed facilities [4]. Combined, architectural concept and architectural project comprise the design documentation.

A developer is a corporate entity or an individual who carries out the construction, reconstruction, major overhaul, demolition of capital construction facilities, engineering surveying, and drafting the design documentation. The developer is entitled to exercise its powers both on its own lot and on the land plot belonging to a different rights holder. Such rights holder could be an entity of any ownership type, an individual entrepreneur, an extra budgetary fund, a state corporation (for example Rosatom, Roskosmos, etc.), a state authority, or a local government authority.

Customers may transfer their functions to another party like technical customers [1].

A technical customer is always a corporate entity that, as assigned by and on behalf of the customer, enters into agreements on engineering surveying, drafting design documentation, construction, reconstruction, major overhaul, and demolition of capital construction facilities. The technical customer also prepares assignments for the abovementioned works, provides the necessary materials and documents to those who perform the works, approves the design documentation, and signs all documents to obtain an approval for commissioning. A technical customer must be a member of a self-regulatory organization operating in the field of engineering surveying, architectural and building design, construction, reconstruction, major overhaul, and demolition of capital construction facilities [1].

A technical director is an individual who organizes construction and renovation works, monitors the work schedule and design documentation compliance, provides all materials and checks the expediency. He/she also takes measures to eliminate violations related to security, and informs the developer on any issues that arise during the construction. 
All abovementioned parties carry out the construction works and bear responsibility for the quality of construction works. In this paper, the authors analyze the stage of construction that leads directly to safety of buildings and facilities. This is the monitoring and supervision stage that is necessary to obtain the compliance assessment at commissioning of the capital construction facility. At this stage, the main parties are regulatory and supervision authorities, which have become one of the subject matters of this paper.

\section{Materials and methods}

Nowadays, the breakdown of buildings and their parts is quite common. In August 2019, a wall of the reconstructed building in Novosibirsk collapsed leaving three construction workers dead. In September 2019, a five-storey building collapsed in Moscow Oblast leaving three workers who were clearing the debris dead. These examples indicate that construction workers violate the standards. It's not just low levels of competence of construction workers and striving for commercial benefits which result in shortened construction period that leads to construction standard violations; negligence and unfair practices of government authorities are part of it too because it's the authorities who issue permissions for construction and commissioning.

The constitutional right to dwell is one the main natural rights of humans [2]. The need in dwelling is always relevant since the number of people is only increasing including Russia, and, due to the growth in prosperity, every young family would choose to live separately. The demand for apartments will continue to grow.

The transfer to market economy made it possible for private construction companies to participate in the construction services sector along with the government. The authors point out the annual growth of private construction companies, which directly indicates the increase in demand in services of the aforesaid construction professionals (Table 1) [5].

Table 1. Annual growth of private construction companies

\begin{tabular}{|l|c|c|c|c|c|c|}
\hline & \multicolumn{2}{|c|}{2015} & \multicolumn{2}{c|}{2016} & \multicolumn{2}{c|}{2017} \\
\hline $\begin{array}{l}\text { Number of } \\
\text { active con- }\end{array}$ & State & Private & State & Private & State & Private \\
\cline { 2 - 7 } $\begin{array}{l}\text { struction } \\
\text { companies }\end{array}$ & 832 & 229,943 & 778 & 269,54 & 759 & 276,94 \\
& & & 8 & & 4 \\
\hline
\end{tabular}

The available data shows that competition has increased: the construction companies are interested in good business practices that would help them improve their good reputation and attract more clients. However, that same competition is the main reason for various violations, which may sometimes lead to unfortunate consequences. The growth of the private construction sector entails the increased risk of low quality and unfair construction of buildings and facilities. During the Soviet times, the government was the only player on the market: it carried out the construction works and monitored the process at all stages (hence the delayed construction typical of the USSR times) while today the government only reserves the right to carry out monitoring and supervision.

\section{Results}

CPC of the Russian Federation is the main statute that regulates every stage of city planning activities including the basics of construction monitoring and supervision. The complexity of construction monitoring and supervision results in a need for further detailed regulatory activity, which is evidenced in federal government agencies acts. The requirements im- 
posed on construction companies for compliance assessment are specified by the Federal Law No. 384-FZ On Technical Regulations for Safety of Buildings and Facilities as of December 30, 2009 [6].

The Decree of the Government of the Russian Federation No. 54 On State Construction Supervision in the Russian Federation as of February 1, 2006, the Decree of the Government of the Russian Federation No. 702 On Approval of Rules for Determination by Federal Government Agencies of Causes for Violation of City Planning Activity as of November 20, 2006, the Regulation on State Construction Supervision in the Russian Federation, and some further orders by the Federal Service for Environmental, Technological and Nuclear Supervision, being the main subject of state construction supervision, regulate the issues of construction supervision.

The construction supervision is less regulated by the federal government and, along with the CPC of the Russian Federation, is governed by the Decree of the Government of the Russian Federation No. 468 On the Procedure for Construction Monitoring upon Construction, Reconstruction and Major Overhaul of Capital Construction Facilities as of June 21,2010 . There also are a number of standard specifications related to construction monitoring, and the construction monitoring engineer job descriptions that are not approved at the federal level.

The authors have identified the gaps in laws that regulate construction at the stage of monitoring, supervision, and compliance assessment, and introduced a few recommendations on how to improve elements of construction-related offences for the Code of the Russian Federation on Administrative Offences (hereinafter referred to as CAO).

\section{Discussion}

It is important to distinguish between construction monitoring and construction supervision.

The construction monitoring is regulated by Art. 53 of CPC of the Russian Federation and by the Decree of the Government of the Russian Federation No. 468 On the Procedure for Construction Monitoring upon Construction, Reconstruction and Major Overhaul of Capital Construction Facilities as of June 21, 2010.

The construction monitoring is carried out for compliance assessment of works versus the design documentation, requirements of technical regulations, results of engineering surveying, construction requirements established by the city planning plan of the land plot as of the day of construction approval, and to determine the compliance with the approved use of the plot and specified restrictions [1].

The monitoring is carried out by contractor, developer, technical customer, designer, or any other persons with whom the developer or technical customer has entered into a construction monitoring agreement [7].

Processes like construction, reconstruction, or major overhaul, regardless of sources of financing, are subject to construction monitoring.

The inspection takes place during the surveying of hidden works and provisional acceptance that influence the safety of facilities, and final acceptance. The final inspection is the last stage of construction monitoring.

If the object is constructed out of federal budget resources in full or partially, the construction monitoring is conducted by the federal government agency.

Construction design supervision is carried out as part of construction monitoring process. The purpose of the former is for the designer of the design documentation to make sure the construction works comply with the documents. The construction design supervision is mandatory for works at hazardous production facilities or if the need for construction design supervision is established in the agreement with the designer at the stage of drafting the design documentation. 
The construction supervision is established by Art. 54 of CPC of the Russian Federation and by the Decree of the Government of the Russian Federation No. 54 On State Construction Supervision in the Russian Federation as of February 1, 2006.

The construction supervision is carried out for capital construction facilities, whose design documentation is subject to regulatory assessment [1]. The cases of mandatory regulatory assessment of design documentation are established by Art. 49 of CPC of the Russian Federation. The construction supervision includes firefighting, sanitary and epidemiological, and environmental supervision.

The subject of the construction supervision is first and foremost the Federal Service for Environmental, Technological and Nuclear Supervision which carries out the supervision with regard to the facilities being constructed in various constituent entities of Russia, defence and security facilities, highways of federal importance, cultural heritage sites of federal importance, hazardous, technically complicated and unique facilities [8]. The construction supervision is also carried out by Rosatom the state corporation, upon construction and reconstruction of nuclear facilities, and by the executive authorities of constituent entities of Russia with regard to all other facilities.

During the monitoring process, the compliance with requirements of technical regulations and design documentation is being checked. The violations of said requirements might cause damage to life and health of humans. The construction supervision entails the assessment of compliance of performed works and applied materials with the requirements of the city planning law. The results of the construction monitoring and supervision are registered in the final acts.

Oftentimes, the construction errors are detected after the commissioning, when elimination of such errors is impossible without reconstruction or demolition. Imposition of sanctions is the most effective way of preventing adverse situations associated with the untimely detection of violated technical regulations.

Any sanction has two functions, the preventative one, and the punitive one. The preventative function prevents the violation by specifying liability in an agreement. The punitive function enforces the established liability by virtue of law.

The preventative function, in case of construction, is very relevant since it is often not implemented. This is caused by an insufficient number of city planning clauses in the Russian administrative law. In addition, the established clauses address mitigated liabilities, according to the authors. Such a situation leads to violations, which are not even prohibited by law, or to nominal liability that can in no way affect the fate of the violator.

For example, the liability of construction monitoring parties, including construction design supervisors, is contained as a fine or penalty in a civil law contract entered into by the parties. The authors believe that such liability is not effective for many reasons. First, the good reputation of the violator - the construction company - is not affected. Second, it opens up an option for corrupt actions. Third, errors introduced at the monitoring/supervision stage are hard to detect in the construction process chain when investigating the collapse cases.

\section{Conclusions}

Currently, the sanctions aimed at construction violations are established by the CAO of the Russian Federation and the Criminal Code of the Russian Federation (hereinafter referred to as CC).

The subject matter of this article is administrative offences. The CAO of the Russian Federation contains more than forty clauses [9]. The authors referred to administrative offences since, despite the lower social danger than that of crimes, these offences act as warning of severe consequences when coerced. 
The comparison of administrative offences and criminal offences lays out the following differences. First, an administrative offence does not entail grievous damage to health that may result in death.

Second, the subject of administrative offence could be an individual, a corporate entity, or a government official. Only individuals may be charged with a criminal offence.

Third, the sanction type and amount of penalty for an administrative offence is different for every party. The lowest penalty is established for individuals, while the heaviest is for government officials. There is an established penalty for corporate entities as well.

Experience shows that penalty is ineffective for government officials. Once the penalty has been paid, an offender continues to exercise his/her powers without any restrictions. The authors believe that the most effective administrative punishment in the field of construction would be temporary suspension of activities of an individual or corporate entity, as well as suspension of government officials. The consequences of such punishment are evidently negative for offenders, damage their reputation, and limit income sources.

The following construction violations are considered punishable under the CAO of the Russian Federation:

1. breach of design documentation, failure to comply with the requirements of technical regulations and standards, other regulatory acts;

Incompliance with design documentation and execution of works which deliberately do not comply with the technical regulations and standards is considered to be an infringement of operating reliability of erected buildings and structures. Operating reliability means the safe conditions of construction activities: ensuring fire safety, health and disease control, environmental safety etc. Violation of either or all of those categories leads to violation of the federal legislation, and the operation of such building will no longer be allowed. The use of the capital construction facility for which the safety regulations were violated frequently leads to the damage of the facility or inflicts harm on people.

2. lack of construction approval in cases where it is mandatory;

Article 51 of the Civil Code of the Russian Federation establishes a number of cases of mandatory building permission procurement. Building permit confirms the fact of conformity of design documentation with the requirements of city planning regulations, area planning project and area demarcation plan. Such permit entitles the developer to build and redesign the capital construction facility [1].

The Civil Code of the Russian Federation contains both the cases of mandatory building permission procurement and the cases where the construction is possible without the permission [1].

For example, no building permit is needed in the following cases:

- Construction, redesign of a garage with no intent of carrying out entrepreneurial activities;

- Construction, redesign of a garden house;

- Construction of a single-family residence with at least three stories;

- Construction, redesign of facilities which are not the capital construction facilities;

- Construction of additional use facilities;

- Changes in the capital construction facility which do not change its characteristics of reliability and safety;

- Construction of embassies, consulates;

- Construction of drill holes;

- Construction, redesign of facilities for natural gas transportation;

- etc.

The danger of construction without mandatory building permit is in complexity of architectural and building design of the plot, mispresentation of the appearance of the said 
area and in threat to public, environmental and fire safety. Construction monitoring and supervision, the most important part of construction cycle, is not carried out for construction without a permit. Which means that there is no evidence of compliance with the city planning regulations and technical regulations. Construction without a permit also has a negative effect on the economy, since the developer does not pay the required fees to the city.

3. design documentation and engineering surveying being drafted by a person who is not a member of a self-governing organization when such membership is mandatory.

Part 2 of article 47 of the Civil Code of the Russian Federation establishes that engineering surveying shall be carried out exclusively by individual entrepreneurs or legal entities who are members of a self-governing organization. Such organization represented by an engineering surveying expert provides the necessary services [1].

Engineering surveying is carried out to obtain the following:

- information on natural conditions and forecast of the changes to the area subject to construction;

- information on man-made factors affecting the environment;

- materials necessary for feasibility evaluation of building/structure arrangement;

- materials necessary for making design decisions with regard to buildings, structures;

- materials necessary for designing engineering protection of capital construction facilities;

- materials necessary for development of materials for environment protection;

- materials facilitating the analysis of foundation, structures, engineering protection;

- materials necessary for development of solutions for preventive measures.

The following violations detected during construction monitoring and supervision are considered punishable under the CAO of the Russian Federation:

1) Failure to meet the deadline to notify executive authorities authorized to carry out the construction supervision at the start of construction;

A notification on the start of construction is important because it allows a regulatory body to understand when it's practical to carry out the first inspection. The following documents should be attached to the notification:

- building permit;

- complete design documentation with all appendices;

- positive expert examination, in cases where it's required by law;

- other documents.

The notification should be submitted within seven (7) days from the start of construction [1]. Submitting notification after the start of construction is considered a serious violation of city planning legislation.

2) Further construction works without a confirmation that violations found during construction supervision have been eliminated;

If the developer committed violations during construction, the government authority issues an order to eliminate the revealed defects after the inspection. The order specifies the type of violation, the legal act or a technical regulation, the requirements of which were violated, and the terms of elimination of such violations. If the developer resumes construction prior to obtaining a certification from the government authority confirming the elimination of violation, it is considered a serious violation, since in doing so the developer brings into question the safety of building operation.

3) Issue of a commissioning approval with no expert assessment after the construction supervision in cases when it is mandatory.

Commissioning approval is a document which finalizes the last stage of construction. This document is issued only after the developer notifies a government authority on the end of construction and receives a statement of conformity. If there are no grounds for issue of 
the statement of conformity, the developer is issued a decision on refusal to grant a statement until the violations are eliminated. Faced with refusal to grant a statement of conformity, the developer finds himself in a complicated position where he needs to eliminate the defects as soon as possible without major financial expenses. Sometimes due to the need to extend the terms and costs of violation elimination, the construction passes to the delayed construction category. Oftentimes the developer obtains the commissioning approval years after the first attempt to obtain it.

As a result of the research, the following gaps in laws have been identified:

1. Not all wrongdoings of monitoring and supervising agencies are punishable.

Considering the role of such agencies in the process of construction of any buildings and structures, the officials should be motivated to act strictly according to law. In cases of administrative violations, the fear of punishment should be the motivation.

2. The general nature of illegal actions combines many different actions of various construction parties at the monitoring and supervision stage.

A number of city planning parties participates at any given construction stage, and each of them influences the course of construction and the possibility of violations. Each city planning party should be a subject of administrative violation in the field of city planning. This will help decrease the number of minor construction violations, which in aggregate lead to a punishable administrative violation.

3. Sanctions for construction administrative offences are nominal and presented as a fine or penalty, which is incomparable with the level of public danger that might be the consequence of improper exercise of powers by responsible government officials.

Fine is considered the softest type of punishment. Within 12 months of the fine payment, the person is considered to be free of any prior administrative violations. The authors believe it to be reasonable to establish such type of administrative punishment as removal officials of regulatory authorities from office when they commit violations. Loss of employment and salary should motivate the officials to act according to law.

The authors have advised to specify the following administrative offences in terms of wrongdoings:

1. Provision of knowingly false certifying documents following the results of construction monitoring of a facility, the construction/reconstruction of which is planned out of federal budget resources in full or partially;

2. Failure to notify the state agencies carrying out the construction supervision on accidents at capital construction facilities;

3. Violation of the customer's expense limits for construction monitoring during construction of the capital construction facility, which is financed out of federal budget in full or partially;

4. Signing of documents by a government official that contain data that fails to correspond to the actual quality of construction works or materials;

5. Violation of terms of procedure for acceptance of a capital construction facility;

6. Signing of an acceptance certificate for construction works that violate the design documentation or technical regulations.

7. Failure to perform or improper performance of construction monitoring or construction design supervision as established by regulatory acts or a civil law contract.

\section{References}


1. O.M. Smirnova, Y.A. Belentsov, A.M. Kharitonov, Journal of Traffic and Transportation Engineering 6(4), 407-417 (2019) doi: 10.1016/j.jtte.2017.12.004

2. Yu.A. Belentsov, O.M. Smirnova, International Journal of Civil Engineering and Technology 9(11), 2999-3005 (2018)

3. L.F. Kazanskaya, O.M. Smirnova, International Journal of Civil Engineering and Technology, 9(11), 3006-3012 (2018)

4. V. Alpatov, A. Sakharov, IOP Conference Series: Materials Science and Engineering 365(6), 062022 (2018). doi:10.1088/1757-899X/365/6/062022

5. D. Chernyshev, V. Alpatov, MATEC Web of Conferences 117, 00028 (2017). DOI: 10.1051/matecconf/201711700028

6. V. Alpatov, MATEC Web of Conferences 117, p. 00007 (2017). DOI: 10.1051/matecconf/201711700007

7. Kalinina, L. Pushkareva, A. Rybakova, Amazonia Investiga 8(22), 40-50 (2019).

8. S. A. Chunikhin, E. A. Kuzmin, L. V. Pushkareva, Entrepreneurship and Sustainability Issues 6(4), 1663-1679 (2019). doi:10.9770/jesi.2019.6.4(8)

9. W. Strielkowski, E. Volkova, L. Pushkareva, D. Streimikiene, Energies 12(7), 1392, (2019). DOI: 10.3390/en12071392 